\title{
Development and validation of a revised instrument to measure burden of long-term medicines use: the Living with Medicines Questionnaire version 3
}

This article was published in the following Dove Press journal: Patient Related Outcome Measures

\section{Barbra Katusiime \\ Sarah A Corlett \\ Janet Krska}

Medway School of Pharmacy, The Universities of Greenwich and Kent, Chatham Maritime, UK
Correspondence: Janet Krska Medway School of Pharmacy, The Universities of Greenwich and Kent at Medway, Anson Building, Central Avenue, Chatham Maritime, Chatham, Kent ME4 4TB, UK

Tel +44I634202950

Email j.krska@kent.ac.uk
Objectives: To revise the Living with Medicines Questionnaire version 2 (LMQ-2), which measures the burden of using prescribed medicines, to include cost and expand side effects and social issues.

Methods: New statements were developed and validated through cognitive interviews with medicine users, and these and a global visual analog scale (VAS) were added to the 42-item LMQ-2. Construct validity was assessed through exploratory and confirmatory factor analyses using an online public survey. Criterion-related validity was measured against the Treatment Satisfaction Questionnaire with Medication (TSQM-II) and the EuroQoL 5-level quality of life measure (EQ-5D-5L), in patients using community pharmacies, general practices, and outpatient clinics. Reliability was assessed by test-retest using online public distribution.

Results: The 58-item interim instrument $(n=729)$ was reduced to 41 items after factor analysis, which confirmed an eight-domain structure: relationships with health professionals, practicalities, interferences, effectiveness, side effects, concerns, cost, and autonomy, constructed as medicine burden. All subscales, except autonomy, were loaded onto this construct and showed acceptable internal consistency. LMQ-VAS correlated with total LMQ scores $(r=0.571)$. Criterion validation $(n=422)$ demonstrated total LMQ scores negatively correlated with TSQM scores for global satisfaction ( $r=-0.616)$; domain scores showed similar correlations: effectiveness $(r=-0.628)$, side effects $(r=-0.597)$, and practicalities $(r=-0.529)$. Total LMQ score was negatively correlated with EQ VAS ( $r=-0.383$ ) and showed weak/moderate relationships with individual EQ-5D-5L dimensions. Test-retest $(\mathrm{n}=30)$ reliability showed intra-class correlation coefficients of 0.954 (total LMQ score), 0.733-0.929 (domain scores), and 0.789 (global item).

Conclusion: The LMQ version 3 (LMQ-3) instrument has acceptable construct, criterionrelated and known-groups validity, and is internally consistent as a measure of medicine burden, although reliability requires further confirmation. It could be used to measure the outcome of interventions designed to reduce the burden of polypharmacy.

Keywords: medicine burden, patient experience, polypharmacy, long-term conditions

\section{Introduction}

Polypharmacy, defined as the use of multiple medicines on a daily basis by an individual, is a growing phenomenon worldwide, due to increases in life expectancy and the prevalence of chronic medical conditions such as cardiovascular disease, type 2 diabetes, arthritis, osteoporosis, and the increasing use of medicines to manage these conditions. ${ }^{1}$ However, while the number of medicines is potentially an indicator of the 
frequency with which problems such as drug interactions may occur, ${ }^{2}$ the patient experience of using multiple medicines is often overlooked. ${ }^{3}$ Yet, it is increasingly recognized that the treatments imposed on individuals by health professionals can be burdensome. Treatment burden, which covers everything patients do to take care of their health, ${ }^{4}$ for most patients includes managing one or more medicines. ${ }^{5}$

From the biomedical perspective, "problematic polypharmacy" has been defined as "multiple medications prescribed inappropriately, or where the intended benefit of the medication is not realized,"6 and a range of interventions have developed which could be used to reduce the number of medicines and optimize their use. ${ }^{7,8}$ A key element of optimizing medicine use in individual patients is the need to understand their experience, including any difficulties and concerns. In England, both the Medicines Optimisation Strategy, developed by the Royal Pharmaceutical Society, ${ }^{9}$ and other national guidance $^{10}$ emphasize the need to determine the patient experience as the first stage in this process. Patients' attitudes toward and experiences with using medicines (positive and negative), their attempts at experimentation and prioritizing, together with issues relating to obtaining medicines and their relationship to prescribers all contribute to the success of any intervention aiming to reduce problems with medicines. ${ }^{11,12}$ A means of quantifying the patient's individual medicine experience is thus essential for practice, while appropriate outcome measures are also necessary for evaluating interventions. However, there are few patient-reported outcome measures available which focus solely on medicine use and which thus have the potential to demonstrate change following interventions designed to reduce problems with medicines in patients using polypharmacy. ${ }^{13,14}$

We have developed an instrument designed to measure the patient experience of long-term polypharmacy conceptualized as medicine burden, the Living with Medicines Questionnaire version 2 (LMQ-2). ${ }^{15}$ This instrument, unlike most other patient-reported measures, was developed from the patient perspective. ${ }^{16}$ The instrument consists of 42 statements accompanied by a 5-point Likert-type scoring system. Eight domains were identified through factor analysis, relating to: perceptions about effectiveness, concerns about medicine use, patient-provider relationships and communication about medicines, practical difficulties, interferences to daily life, autonomy/control over medicine, and acceptance of medicine use, all areas which have been cited by users of long-term medicines as burdensome. ${ }^{15}$

Some respondents to this instrument identified that it lacked a domain covering cost burden, which can be an issue of concern to some patients, even in countries with good access to free medicines. ${ }^{17-19}$ Cost burden has also been recognized as potentially important in the measurement of overall treatment burden. ${ }^{4}$ Other respondents suggested that greater emphasis needed to be placed on the social aspects of using medicines and experiences of side effects. Review of the 42 statements included in the LMQ-2 showed that the two covering social aspects were indeed limited and the two covering side effects did not emphasize the effect of these on daily life. We therefore set out to develop a revised version of this instrument, which addressed these issues more fully, without enlarging it, and to undertake a rigorous validation of the revised instrument.

\section{Methods}

\section{Item generation and content validation}

New content was based on reanalysis of the 21 patient interviews used to elicit concepts in the original $\mathrm{LMQ}^{20}$ and free-text comments from survey participants completing this version of the instrument, ${ }^{15}$ along with qualitative studies reported in the literature. ${ }^{12,21-23}$ All items were reviewed and new items added through discussions among the researchers (BK, SC, JK). An interim instrument, which included 58 items (LMQ-2.1), was developed and assessed for face and content validity through cognitive interviews with long-term medicine users, recruited via a public engagement group. Members of the group who met the inclusion criteria (18 years or older, using regular prescription medicines, able to read and communicate in English, and living in England) participated themselves and/or recruited other eligible participants through snowballing.

\section{Study instruments}

The interim version (LMQ-2.1) was similar to the LMQ-2, but contained 58 statements, rated on a 5-point Likert-type scale (strongly agree to strongly disagree), utilizing reverse scoring as appropriate with higher scores reflecting worse experiences of medicine use (higher medicine burden). A $10 \mathrm{~cm}$ visual analog scale (VAS) was also included as a global item, with anchors indicating "no burden at all" to "extremely burdensome", to assess the overall medicine burden (VAS-burden). Participant characteristics gathered included general demographics as well as number, frequency, and type of formulation of regular medicines and support with using medicines. The process of assessing construct validity in Stage 1 resulted in item reduction; therefore, the instrument used for Stages 2 and 3 (LMQ-3) differed in the number of Likert-type statements. 
The instruments used to assess criterion-related validity of the LMQ-3 were the Treatment Satisfaction Questionnaire with Medication (TSQM-II), an 11-item instrument which measures satisfaction with prescription medicines in four subscales (effectiveness, side effects, convenience, and global satisfaction), and the EuroQoL 5-level quality of life measure (EQ-5D-5L). The latter is a widely used five-item measure of health-related quality of life (HRQoL), including a VAS which measures overall health status. Permission to use the TSQM-II and the EQ-5D-5L (UK English versions) was granted by the Quintiles group (Inc) and the EuroQol Research Foundation, respectively.

\section{Psychometric testing}

Different groups of participants were involved in psychometric testing of the LMQ, which was done over three stages. All participants were required to answer screening questions to ensure they met inclusion criteria stated earlier before completing the instrument. Consent was implied by return of completed paper questionnaires or electronic submission of online responses. IBM SPSS version 22 and AMOS version 22 were used for statistical analyses.

\section{Construct validity and internal consistency (Stage I)}

This used an online survey, publicized via social media, including Twitter and Facebook posts through UK patient organizations, and health websites which permitted access to their memberships. A missing data analysis was undertaken, then respondents who had completed all 58 items (LMQ-2.1) were included in exploratory (EFA) and confirmatory factor analyses (CFA) to elucidate and confirm the underlying factor structure of the instrument. The sample was split randomly into two and both subsamples were assessed for normality prior to use in EFA and CFA. Sample size adequacy for factor analyses was examined via Kaiser-Meyer-Olkin Measure (KMO) and by the number of items per response, though there is no universally accepted method. ${ }^{24}$ Bartlett's Test of Sphericity and Pearson's correlation matrix were used to assess factorability of data and potential multi-collinearity. All 58 items (LMQ-2.1) were initially subjected to principal axis factoring, using oblique factor rotation (promax) on the basis that domains were inter-related. Kaiser's criterion (eigenvalues $>1$ ), scree plots, and parallel analysis were used to determine the number of factors for EFA.

Criteria for item reduction were: low communalities $(<0.3)$, poor loadings on the primary factor $(<0.32)$, and/ or cross loading $(>0.4)$ on two or more factors. ${ }^{25-27}$ Items loading on unstable (weak) factors, which had fewer than three items, and items with floor and ceiling effects were considered for removal, the latter defined as having skewness and kurtosis values above two or over $65 \%$ selecting either of the extreme options.

The second half of the dataset was subjected to CFA to test a higher-order (second-order) model involving only the remaining items, using maximum likelihood estimation, based on the strength of correlations among domains derived from the EFA, and preliminary testing of a first-order model. We hypothesized that medicine burden could explain the variation among all domains within the LMQ. Goodness-of-fit indices used to assess the second-order model were: relative chi-square (chi-square statistic/degrees of freedom), root mean square error of approximation (RMSEA) with $90 \%$ confidence interval $(90 \% \mathrm{CI})$, comparative fit index (CFI), and Tucker-Lewis index (TLI). The magnitude and direction of factor loadings was also examined to ascertain the relative contribution of different items and/or domains to the models. ${ }^{28,29}$

In addition, LMQ total scores were compared to scores from the VAS, "Overall, how much of a burden do you feel your medicines are to you?" using Pearson's correlation coefficient to add further to construct validation. Cronbach's $\alpha$ was examined to assess the internal consistency of the LMQ-3 subscales.

\section{Criterion-related validity (Stage 2)}

The LMQ-3 together with two other relevant measures, the TSQM-II ${ }^{30,31}$ and a HRQoL measure (EQ-5D-5L), ${ }^{32}$ were distributed by hand to patients in community pharmacies, general practices, and hospital outpatient waiting areas. Spearman's correlation coefficients were used to assess relationships between the three instruments, with coefficients $<0.35$ interpreted as weak, $0.35-0.5$ as moderate, and $>0.5$ as strong, taking a $p$-value of 0.05 as representing statistical significance. ${ }^{33}$ A negative relationship between overall medicine burden and treatment satisfaction (measured with the TSQM-II) was hypothesized, and LMQ-3 domain scores for side effects, lack of effectiveness, and practical difficulties were predicted to show negative correlations with scores on the TSQM-II global satisfaction, satisfaction with side effects, satisfaction with effectiveness, and satisfaction with convenience subscales. Medicine burden was hypothesized to be negatively, but weakly, related to overall health status (measured with the EQ VAS), since the two constructs were hypothesized as being distinct.

\section{Known-groups validity}

The same population was used to assess known-groups validity, using the demographic data contained in the LMQ-3. Medicine-related burden was hypothesized to relate posi- 
tively with regimen complexity, particularly the number of medicines, frequency of administration, and the formulation used. The need for social support with managing medicines was also predicted to indicate higher medicine burden. In addition, cost burden was hypothesized to be associated with having to make co-payments for prescribed medicines and living in areas of higher relative deprivation. Relationships were assessed using independent samples $t$-tests or one-way analysis of variance.

\section{Test-retest reliability (Stage 3)}

This was assessed using online distribution to a cohort of the general public who had signed up to a research unit, with the instrument redistributed to respondents after 2 weeks. Stability of scores was assessed for subscales (domains), the LMQ-3 total score, and the global VAS score using intra-class correlation coefficients (ICCs) and their 95\% confidence intervals, which were estimated by using the two-way mixed effects model for absolute agreement where rater effects were assumed constant, with an ICC value of $\geq 0.7$ considered as acceptable. $^{34}$

\section{Missing data analysis}

The patterns of missing responses to Stage 1 and Stage 2 were assessed, and for Stages 2 and 3, the demographic characteristics of those with partial responses compared to those who fully completed the LMQ-3, using chi-squared tests, where appropriate.

\section{Ethical approval}

Approval was obtained from the Medway School of Pharmacy research ethics committee for studies involving the general public (instrument revision, Stages 1 and 3). Approval for stage 2 was granted from the National Health Service research ethics committee South Central Oxford C and relevant research governance obtained. All procedures performed were in accordance with the ethical standards of the institutional or national research committee and with the 1964 Helsinki Declaration and its later amendments or comparable ethical standards.

\section{Results}

\section{Completion rates and participant demographics}

Eleven participants, six of whom were male, aged 42-75 years and using between 1 and 12 regular medicines participated in the cognitive interviews. Recruitment was terminated after the 11th interview, as no new problems with the revised instrument emerged from the interviews, which showed similarities in interpretation of questionnaire items and general concepts underpinning the LMQ and no unique item meanings (i.e., data saturation). There were no major comprehension problems, and most participants understood the concept of the term burden as used in the VAS.

The few minor uncertainties which arose were resolved through discussions among the team, and revisions were made to item wording.

The details of respondent numbers for the remainder of the study are shown in Figure 1. A total of 1223 individuals accessed the online survey in Stage 1 over a 3-month period, of whom 361 did not respond to any questions at all. The 729 participants who fully completed all 58 items (59.6\% completion rate) were divided into two samples for EFA (366) and CFA (363). For Stage 2 (criterion-related validation), 1306 questionnaires were distributed: 220 in GP practices, 150 in community pharmacies, and 936 in outpatient clinics. Overall, 422 completed questionnaires were returned, representing a $32.3 \%$ completion rate, $36.4 \%(\mathrm{n}=80), 44.7 \%(\mathrm{n}=67)$, and $29.4 \%$ ( $n=275$ ) for GP practices, community pharmacies, and outpatient clinics, respectively. Item-level completion rates were high $(91.9 \%-100 \%)$, with 336 (79.6\%) fully completing all 41 Likert-type statements. The Stage 3 invitation to complete the test-retest questionnaire was sent to $\sim 300$ members of a research unit; however, no data were available on the proportion of the members eligible for this stage. Forty-five people responded: 35 (78\%) completed the baseline questionnaire and $30(86 \%)$ fully completed the retest questionnaire.

Demographic details of all the three participant groups are shown in Table 1. Overall, more than half of all participants were female, the majority were white and the number of medicines used was similar among all groups, the highest number used being 26 . The patients involved in assessing criterion-related and known-groups validity (Stage 2) were older and had lower education levels than the public who were involved in the factor analysis study (Stage 1). There were sufficient numbers of respondents in Stage 2 who used medicines more than once a day, needed support from others to manage their medicines, and had to pay for their medicines to enable assessment of known-groups validity.

\section{Construct validity and internal consistency (Stage I)}

Responses to individual LMQ items were normally distributed, all having skewness values $<2.0$; only five items had skewness values $>2$. Potential floor/ceiling effects were observed for only five items, the most skewed having 59.1\% 

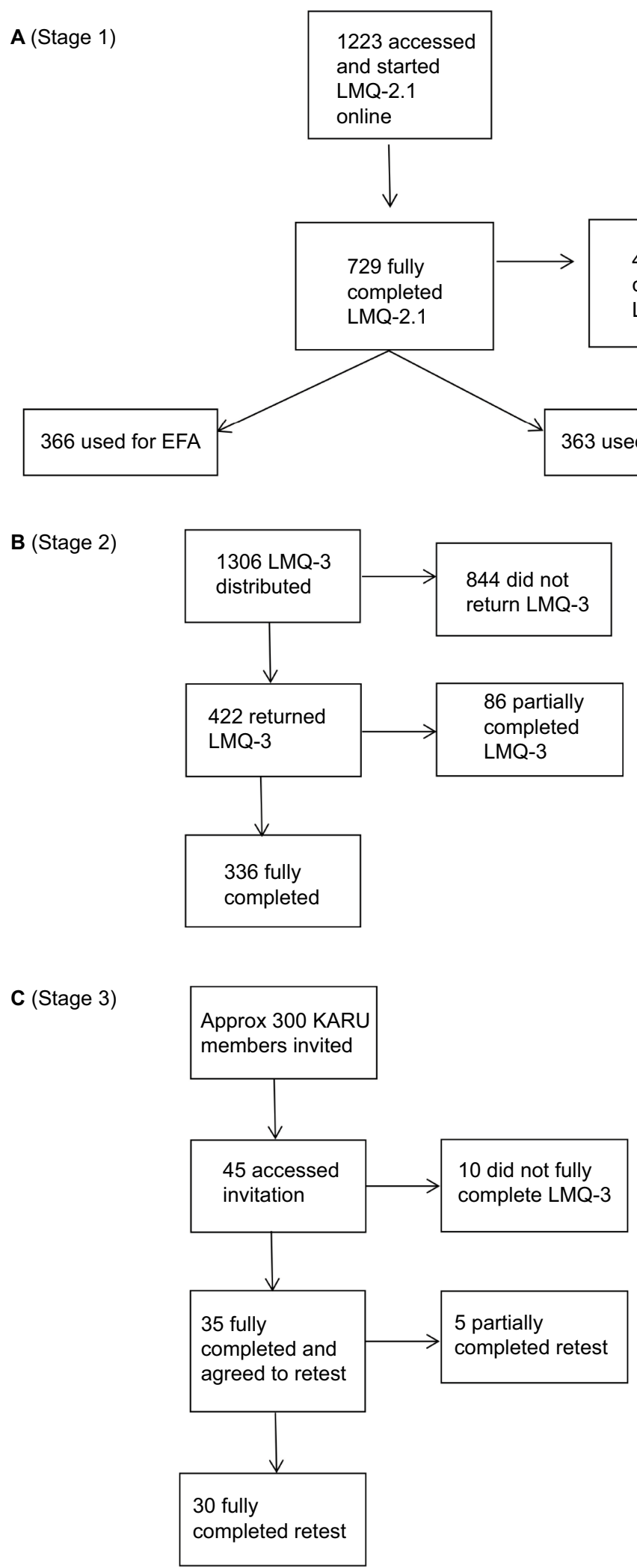

Figure I Flow diagrams illustrating respondent numbers in each stage of the study.

Abbreviations: LMQ, Living with Medicines Questionnaire; EFA, exploratory factor analyses; CFA, confirmatory factor analyses; KARU; Kent Adult Research Unit.

of respondents selecting the lowest scoring option. The EFA sample size $(n=366)$ met the minimum requirements for factor analysis of at least five participants per item, a
KMO value of 0.902 (acceptable values $\geq 0.6$ ) and Bartlett's Test of Sphericity being significant (chi-square $=10,585.7$, $d f=1653 ; p<0.001) .{ }^{35}$ All inter-variable correlations were 
Table I Characteristics of study participants

\begin{tabular}{|c|c|c|c|c|c|}
\hline \multirow[b]{3}{*}{ Characteristics } & & \multicolumn{2}{|l|}{ Stage I } & \multirow{3}{*}{$\begin{array}{l}\text { Stage } 2 \\
\text { Criterion } \\
\text { validation study } \\
\mathbf{n}(\%)\end{array}$} & \multirow{3}{*}{$\begin{array}{l}\text { Stage } 3 \\
\text { Test- } \\
\text { retest } \\
\mathrm{n}(\%)\end{array}$} \\
\hline & & \multicolumn{2}{|c|}{ Construct validation study } & & \\
\hline & & $\begin{array}{l}\text { EFA subset } \\
\text { n (\%) }\end{array}$ & $\begin{array}{l}\text { CFA subset } \\
\text { n (\%) }\end{array}$ & & \\
\hline \multirow[t]{2}{*}{ Gender } & Female & $312(86.7)$ & $300(85.0)$ & $208(52.8)$ & $20(67)$ \\
\hline & Male & $48(13.3)(n=360)$ & $53(15.0)(n=353)$ & $186(47.2)(n=394)$ & $10(33)(n=30)$ \\
\hline \multirow[t]{4}{*}{ Age group (years) } & $18-29$ & $25(7.0)$ & $26(7.3)$ & $51(12.1)$ & $\mathrm{I}(3)$ \\
\hline & $30-49$ & $155(43.2)$ & $159(45.0)$ & $81(19.3)$ & I (3) \\
\hline & $50-64$ & $153(42.6)$ & $137(38.7)$ & $118(28.1)$ & $5(17)$ \\
\hline & $\geq 65$ & $26(7.2)(n=359)$ & $32(9.0)(n=354)$ & $170(40.5)(n=420)$ & $23(77)(n=30)$ \\
\hline \multirow[t]{4}{*}{ Education level } & School & $73(20.5)$ & $66(18.7)$ & $158(40.3)$ & $5(17)$ \\
\hline & Technical college & $86(24.2)$ & $93(26.3)$ & 117 (29.9) & $5(17)$ \\
\hline & University & $161(45.2)$ & $168(47.6)$ & $89(22.7)$ & $17(57)$ \\
\hline & Other & $36(10.1)(n=356)$ & $26(7.4)(n=353)$ & $28(7.1)(n=392)$ & $3(10)(n=30)$ \\
\hline \multirow{5}{*}{ Employment status } & Employed & $163(45.8)$ & $168(47.5)$ & $159(38.8)$ & $5(17)$ \\
\hline & Unemployed & $36(10.1)$ & $48(13.5)$ & $44(10.7)$ & $0(0)$ \\
\hline & Retired & $67(18.8)$ & $59(16.7)$ & $187(45.6)$ & $23(77)$ \\
\hline & Full-time student & $10(2.8)$ & $10(2.8)$ & $20(4.9)$ & $0(0)$ \\
\hline & Other & $80(22.5)(n=356)$ & $69(19.5)(n=354)$ & $0(n=4 \mid 0)$ & $2(7)(n=30)$ \\
\hline \multirow[t]{5}{*}{ Ethnicity } & White & $345(96.1)$ & $339(95.8)$ & $353(86.5)$ & $29(97)$ \\
\hline & Asian/Asian British & $3(0.8)$ & $3(0.8)$ & $15(3.7)$ & $0(0)$ \\
\hline & Mixed & $\mathrm{I}(0.3)$ & $6(1.7)$ & $10(2.4$ & I (3) \\
\hline & Black/African/Caribbean & $2(0.6)$ & $2(0.6)$ & $26(2.4)$ & $0(0)$ \\
\hline & Other & $8(2.2)(n=359)$ & $4(I . I)(n=354)$ & $4(1.0)(n=408)$ & $0(0)(n=30)$ \\
\hline \multirow[t]{3}{*}{ Number of medicines } & $\mathrm{I}-4$ & $220(6 I .1)$ & $212(59.9)$ & $236(56.7)$ & $16(53)$ \\
\hline & $5-9$ & $107(29.7)$ & $112(31.6)$ & $126(30.3)$ & $14(47)$ \\
\hline & $\geq 10$ & $33(9.2)(n=360)$ & $30(8.5)(n=354)$ & $54(13.0)(n=4 \mid 6)$ & $0(0)(n=30)$ \\
\hline \multirow[t]{2}{*}{ Formulation used ${ }^{c}$} & Tablets/capsules & $349(95.3)$ & $343(94.5)$ & $374(92.6)$ & $28(93)$ \\
\hline & Any other formulation & $|5|(4 \mid .2)(n=366)$ & $166(45.7)(n=363)$ & $120(29.7(n=404)$ & $16(53)$ \\
\hline Frequency of & Once daily & $160(43.7)$ & $169(46.5)$ & $146(35.9)$ & $18(60)$ \\
\hline \multirow[t]{4}{*}{ medicine use ${ }^{c}$} & Twice daily & $|5|(4 \mid .2)$ & $134(36.9)$ & $136(33.5)$ & $10(33)$ \\
\hline & Three times daily & $76(20.8)$ & $73(20.1)$ & $49(12.1)$ & $6(20)$ \\
\hline & $\geq 4$ times daily & $55(15.0)$ & $65(17.9)$ & $47(11.6)$ & I (3) \\
\hline & Other times ${ }^{\mathrm{a}}$ & $50(13.7)(n=366)$ & $54(14.9)(n=363)$ & $28(6.9)(n=406)$ & $2(7)$ \\
\hline Assisted in using & No - independent & $306(85.2)$ & $309(87.3)$ & $349(85.7)$ & $29(97)$ \\
\hline \multirow[t]{6}{*}{ medicines } & Yes - has a caretaker & $53(14.8)(n=359)$ & $45(12.7)(n=354)$ & $58(14.3)(n=407)$ & I (3) $(n=30)$ \\
\hline & Spouse/partner & $34(64.2)$ & $33(73.3)$ & $33(58.9)$ & I (3) \\
\hline & Relative & $9(17.0)$ & $\mathrm{I}(2.2)$ & $10(17.9)$ & $0(0)$ \\
\hline & Support worker & $4(7.5)$ & $3(6 . .7)$ & $7(12.5)$ & $0(0)$ \\
\hline & Friend & $\mathrm{I}(\mathrm{I} .9)$ & $\mathrm{I}(2.2)$ & $4(7.1)$ & $0(0)$ \\
\hline & Other $^{\mathrm{b}}$ & $5(9.4)(n=53)$ & $7(15.6)(n=45)$ & $2(3.6)(n=56)$ & $0(0)$ \\
\hline \multirow[t]{2}{*}{ Pays for prescriptions } & No & $245(68.1)$ & $248(70.1)$ & $267(66.6)$ & $27(90)$ \\
\hline & Yes & $115(31.9)(n=360)$ & $106(29.9)(n=354)$ & I4I (33.4) & $3(10)(n=30)$ \\
\hline
\end{tabular}

Notes: ancludes medicines PRN, different times of the week, fortnightly, monthly, every 3 months; bincludes nurse or multiple support from relatives, friends, and caretakers. 'participants could choose more than one response option, thus proportions are estimated for each category.

Abbreviations: EFA, exploratory factor analyses; CFA, confirmatory factor analyses; PRN, taken as needed.

$<0.8$, and there was thus no evidence of multi-collinearity (or redundancy) among items. Conversely, most correlations were $>0.3$, indicating sufficient commonality to justify the presence of underlying factors.

The initial EFA solution resolved into 13 factors with eigenvalues $>1$, explaining $63.4 \%$ of the total variance. The scree plot suggested retention of eight factors, while parallel analysis revealed seven factors met statistical inclusion criteria. An eight-factor solution was most stable and conceptually interpretable. The eight factors were termed: interferences with day-to-day life, relationships and communication about medicines, lack of effectiveness, general concerns about medicines, side effects, practical difficulties, cost-related burden, and lack of autonomy/control of medicine use. 
A total of 17 items were deleted from the preliminary 58-item pool after exploratory factor analysis, leaving a 41-item questionnaire (LMQ-3). Table 2 shows the 41 LMQ-3 items retained and the eight-factor structure.

The sample of 363 was adequate for CFA, and multivariate normality was acceptable as judged by Mardia's coefficient $(171.6$, critical ratio $=27.5)$. First-order factor loadings were in the range of $0.396-0.891$ and were statistically significant $(p<0.001)$ for all items. CFA confirmed inter-correlations among factors underlying the LMQ-3, although "autonomy" was least correlated with other factors. In the hypothesized second-order model (Figure 2), factor loadings were in the range of $0.32-0.88$ and statistically significant $(p<0.001)$ for seven domains, being strongest for "interferences" (0.88), "side effects" $(0.85)$, and "concerns" (0.81). "Autonomy" did not load significantly on medicine burden $(0.11, p=0.224)$, but empirical attempts to exclude it were unable to significantly improve overall model fit and the domain was retained based on professional judgment. Relative chi-square values $(2.083$, acceptable value $<3$ ) and RMSEA coefficients $(0.055,90 \%$ CI $0.051-0.058$, acceptable value $<0.06$ ) depicted an adequate model fit, although the TLI and CFI values of 0.866 and 0.874 , respectively, were very slightly below the target of $\geq 0.90$.

All LMQ-3 subscales, except for "autonomy", showed acceptable internal consistency (Cronbach's $\alpha$ coefficients $>0.7$ ) (Table 2). A positive correlation was found between LMQ total scores and VAS burden scores $(r=0.571, p<0.001)$.

\section{Criterion-related validity (Stage 2)}

The correlation between scores on the LMQ-3 total scale and the global satisfaction scale of the TSQM-II was strong and negative ( $r=-0.616)$ as hypothesized, confirming that higher medicine burden was associated with lower satisfaction (Table 3). As predicted, correlations were strongest between thematically comparable subscales of the two instruments: LMQ-3 lack of effectiveness with TSQM-II satisfaction with effectiveness $(r=-0.628)$; LMQ-3 side effect burden with TSQM-II satisfaction with side effects $(r=-0.597)$; and LMQ-3 practical difficulties with TSQM-II satisfaction with convenience of medicine use ( $r=-0.529)$.

Correlations between LMQ-3 total score and EQ-5D-5L scores ranged from 0.284 to $0.436(p<0.01)$, depicting weak to moderate relationships between medicine burden and individual HRQoL dimensions, the weakest correlation being for self-care and the strongest for anxiety/depression. LMQ-3 total score was negatively associated with general health status reported on the EQ VAS $(r=-0.383 ; p<0.01)$, as hypothesized.

\section{Known-groups validity}

There were statistically significant differences in mean LMQ-3 total scores dependent on the number of medicines used, frequency of daily medicine taking, and need for support with managing medicines (Table 4). Age and employment status were not predicted to affect LMQ-3 total scores, but data showed that older people perceived themselves to have lower medicine burden than younger participants, while higher scores were also seen in those who were unemployed. One factor contributing to this latter finding was cost burden, which was higher in the unemployed (mean \pm SD 8.8 \pm 3.2 ) compared to those employed (mean \pm SD 7.3 \pm 3.2$)(p<0.05)$. Total LMQ scores were also higher in those who made a copayment for prescription medicines.

\section{Test-retest reliability (Stage 3)}

The median test-retest duration was 15 days. All eight domain scores had satisfactory ICC values ranging from 0.733 to 0.929 . The total LMQ-3 score was highly correlated between test and retest $(r=0.91)$, mean scores being $91.07 \pm 18.92$ and $92.14 \pm 19.55$, respectively, and the ICC value being 0.954 . In addition, the global item had an ICC of 0.789 .

\section{Missing data analysis}

The online survey used for Stage 1 showed a pattern of non-response that was directly related to the length of the 58-item LMQ-2.1 instrument and its online presentation of 4-5 questions per page (Figure 3). For Stage 2, there were 86 respondents who partially completed the LMQ-3 (Figure 3); the most frequently omitted questions are shown in Table 5 . The majority of missing responses could be due to the view that the statement was of no direct relevance, as there were 44 who missed at least one question covering cost burden, and 18 who only omitted questions from this domain. However, the pattern also suggests that the length of the LMQ-3 was also a potential reason for failure to fully complete the questionnaire. The 86 partial responders were younger, more highly educated, and using fewer medicines than the 336 who fully completed the LMQ-3 (Table 6). The respondents who failed to complete the second questionnaire in Stage 3 were similar in age, education, employment status, and number of medicines used to those who did, but three of the five were male, whereas the majority completing both questionnaires were female. 
Table 2 EFA-derived factor structure of the LMQ-3 $(\mathrm{N}=366)$

\begin{tabular}{|c|c|c|c|c|c|c|c|c|}
\hline \multirow[t]{2}{*}{ Items } & \multicolumn{8}{|c|}{ Derived factors } \\
\hline & Int & Relat & Effec & Conc & SideE & Prac & Cost & Auto \\
\hline \multicolumn{9}{|l|}{ Interferences with day-to-day life $(\alpha=0.865)$} \\
\hline My medicines interfere with my social relationships. & 0.892 & 0.060 & 0.009 & -0.121 & -0.002 & -0.001 & 0.062 & 0.018 \\
\hline My medicines interfere with my social or leisure activities. & 0.779 & 0.078 & -0.022 & 0.139 & -0.015 & -0.052 & -0.079 & 0.000 \\
\hline Taking medicines affects my driving. & 0.690 & -0.045 & -0.064 & 0.030 & -0.034 & -0.039 & -0.002 & -0.023 \\
\hline $\begin{array}{l}\text { Taking medicines causes me problems with daily tasks (such as work, } \\
\text { housework, hobbies). }\end{array}$ & 0.644 & 0.025 & 0.052 & -0.112 & 0.319 & -0.105 & 0.066 & 0.014 \\
\hline My medicines interfere with my sexual life. & 0.643 & 0.036 & 0.006 & -0.036 & 0.056 & 0.011 & 0.088 & -0.023 \\
\hline My life revolves around using my medicines. & 0.480 & 0.034 & -0.078 & 0.089 & 0.102 & 0.066 & 0.052 & 0.023 \\
\hline \multicolumn{9}{|c|}{ Patient-doctor relationships and communication about medicines $(\alpha=0.870)$} \\
\hline My doctor(s) listen to my opinions about my medicines. & 0.032 & 0.810 & -0.051 & -0.018 & -0.028 & 0.048 & -0.042 & 0.047 \\
\hline My doctor(s) take my concerns about side effects seriously. & 0.059 & 0.794 & 0.015 & -0.061 & -0.009 & -0.066 & 0.042 & -0.002 \\
\hline I get enough information about my medicines from my doctor(s). & 0.049 & 0.761 & 0.000 & 0.094 & -0.033 & 0.025 & -0.014 & 0.043 \\
\hline $\begin{array}{l}\text { The health professionals providing my care know enough about me and } \\
\text { my medicines. }\end{array}$ & -0.001 & 0.612 & 0.133 & 0.044 & -0.051 & 0.085 & -0.048 & -0.033 \\
\hline I trust the judgment of my doctor(s) in choosing medicines for me. & 0.001 & 0.556 & 0.152 & 0.027 & 0.007 & 0.137 & -0.031 & -0.085 \\
\hline \multicolumn{9}{|l|}{ Lack of effectiveness $(\alpha=0.85 \mathrm{I})$} \\
\hline My medicines are working. & -0.142 & -0.026 & 0.882 & -0.004 & 0.072 & -0.007 & 0.067 & 0.083 \\
\hline My medicines live up to my expectations. & -0.043 & 0.062 & $0.7 \mathrm{II}$ & 0.084 & 0.066 & 0.057 & 0.040 & 0.064 \\
\hline I am satisfied with the effectiveness of my medicines. & -0.026 & $0.06 \mathrm{I}$ & 0.719 & 0.054 & 0.078 & 0.032 & -0.071 & -0.018 \\
\hline The side effects are worth it for the benefits I get from my me & -0.151 & 0.173 & 0.601 & 0.046 & -0.077 & -0.225 & 0.062 & 0.040 \\
\hline My medicines prevent my condition getting worse. & 0.247 & -0.044 & 0.523 & -0.144 & -0.142 & 0.160 & -0.046 & -0.134 \\
\hline My medicines allow me to live my life as I want to. & 0.345 & 0.106 & 0.525 & 0.017 & -0.084 & 0.023 & -0.087 & -0.007 \\
\hline \multicolumn{9}{|l|}{ General concerns about medicines $(\alpha=0.796)$} \\
\hline $\begin{array}{l}\text { I am concerned about possible damaging long-term effects of taking } \\
\text { medicines. }\end{array}$ & -0.086 & 0.008 & 0.020 & 0.648 & 0.270 & -0.035 & -0.067 & -0.076 \\
\hline I worry that my medicines may interact with each other. & -0.004 & -0.073 & 0.128 & 0.639 & 0.165 & -0.061 & -0.018 & 0.003 \\
\hline I am concerned that I am too reliant on my medicines. & 0.167 & 0.043 & -0.028 & 0.635 & -0.173 & -0.099 & 0.037 & -0.096 \\
\hline I worry that I have to take several medicines at the same time. & -0.056 & -0.091 & 0.061 & 0.550 & -0.003 & 0.135 & 0.126 & -0.091 \\
\hline I am concerned that my medicines interact with alcohol. & 0.339 & -0.069 & -0.015 & 0.505 & -0.171 & -0.169 & 0.060 & 0.158 \\
\hline I feel I need more information about my medicines. & -0.014 & 0.252 & 0.036 & 0.544 & 0.058 & -0.010 & 0.022 & 0.016 \\
\hline I would like more say in the brands of medicines I use. & -0.196 & 0.200 & -0.081 & 0.447 & 0.134 & 0.005 & 0.076 & -0.009 \\
\hline \multicolumn{9}{|l|}{ Side effects $(\alpha=0.90 \mathrm{I})$} \\
\hline The side effects I get from my medicines are bothersome. & 0.131 & -0.099 & -0.072 & 0.054 & 0.812 & 0.063 & -0.027 & 0.024 \\
\hline $\begin{array}{l}\text { The side effects I get from my medicines interfere with my day-to-day life } \\
\text { (e.g., work, housework, sleep). }\end{array}$ & 0.355 & -0.023 & -0.014 & -0.026 & 0.687 & -0.072 & 0.031 & 0.009 \\
\hline $\begin{array}{l}\text { The side effects I get are sometimes worse than the problem for which I } \\
\text { take medicines. }\end{array}$ & 0.051 & 0.029 & 0.078 & 0.030 & 0.647 & 0.016 & -0.042 & 0.007 \\
\hline The side effects I get from my medicines adversely affect my well-being. & 0.346 & 0.019 & 0.020 & 0.016 & 0.612 & -0.040 & -0.028 & 0.013 \\
\hline \multicolumn{9}{|l|}{ Practical difficulties $(\alpha=0.738)$} \\
\hline I find getting my prescriptions from the doctor difficult. & -0.093 & 0.225 & -0.110 & -0.148 & 0.089 & 0.734 & 0.060 & 0.061 \\
\hline It is easy to keep to my medicines routine. & 0.044 & -0.079 & 0.174 & -0.065 & -0.024 & 0.631 & -0.009 & -0.018 \\
\hline I find getting my medicines from the pharmacist difficult. & -0.017 & 0.090 & -0.111 & 0.033 & -0.041 & 0.616 & 0.090 & 0.023 \\
\hline I am comfortable with the times I should take my medicines. & -0.048 & -0.093 & 0.323 & 0.024 & -0.024 & 0.398 & 0.031 & 0.010 \\
\hline I have to put a lot of planning and thought into taking my medicines. & 0.295 & -0.092 & -0.116 & 0.169 & 0.145 & 0.464 & -0.036 & 0.000 \\
\hline I am concerned that I may forget to take my medicines. & 0.170 & -0.139 & -0.056 & 0.343 & -0.162 & 0.421 & -0.139 & 0.172 \\
\hline I find using my medicines difficult. & 0.311 & -0.020 & 0.028 & 0.102 & 0.086 & 0.410 & -0.021 & -0.102 \\
\hline \multicolumn{9}{|l|}{ Cost-related burden $(\alpha=0.80 \mathrm{I})$} \\
\hline I have to pay more than I can afford for my medicines. & 0.081 & -0.039 & 0.029 & 0.028 & -0.062 & 0.004 & 0.838 & 0.032 \\
\hline I sometimes have to choose between buying basic essentials or medicines. & 0.130 & 0.002 & 0.109 & -0.057 & 0.016 & 0.013 & 0.704 & -0.050 \\
\hline I worry about paying for my medicines. & -0.071 & -0.021 & -0.102 & 0.165 & -0.026 & 0.132 & 0.679 & 0.004 \\
\hline \multicolumn{9}{|l|}{ Lack of autonomy/control of medicine use $(\alpha=0.692)$} \\
\hline I can choose whether or not to take my medicines. & 0.051 & -0.036 & 0.005 & 0.000 & -0.012 & -0.029 & -0.020 & 0.732 \\
\hline I can vary the dose of the medicines I take. & -0.102 & 0.008 & 0.086 & -0.179 & 0.089 & 0.035 & 0.033 & 0.668 \\
\hline I can vary the times I take my medicines. & 0.050 & 0.058 & 0.000 & 0.051 & -0.021 & 0.085 & -0.018 & 0.628 \\
\hline
\end{tabular}

Notes: All items are scored so that higher scores reflect worse experiences (higher burden) with medicine use. Statistically significant values are shown in bold. Abbreviations: LMQ-3, Living with Medicines Questionnaire version 3; EFA, exploratory factor analyses; Int, interferences with day-to-day life; Relat, patient-doctor relationships and communication about medicines; Effec, lack of effectiveness; Conc, general concerns about medicines; Prac, practical difficulties; SideE, side effects; Cost, cost-related burden; Auto, lack of autonomy/control over medicine use. 

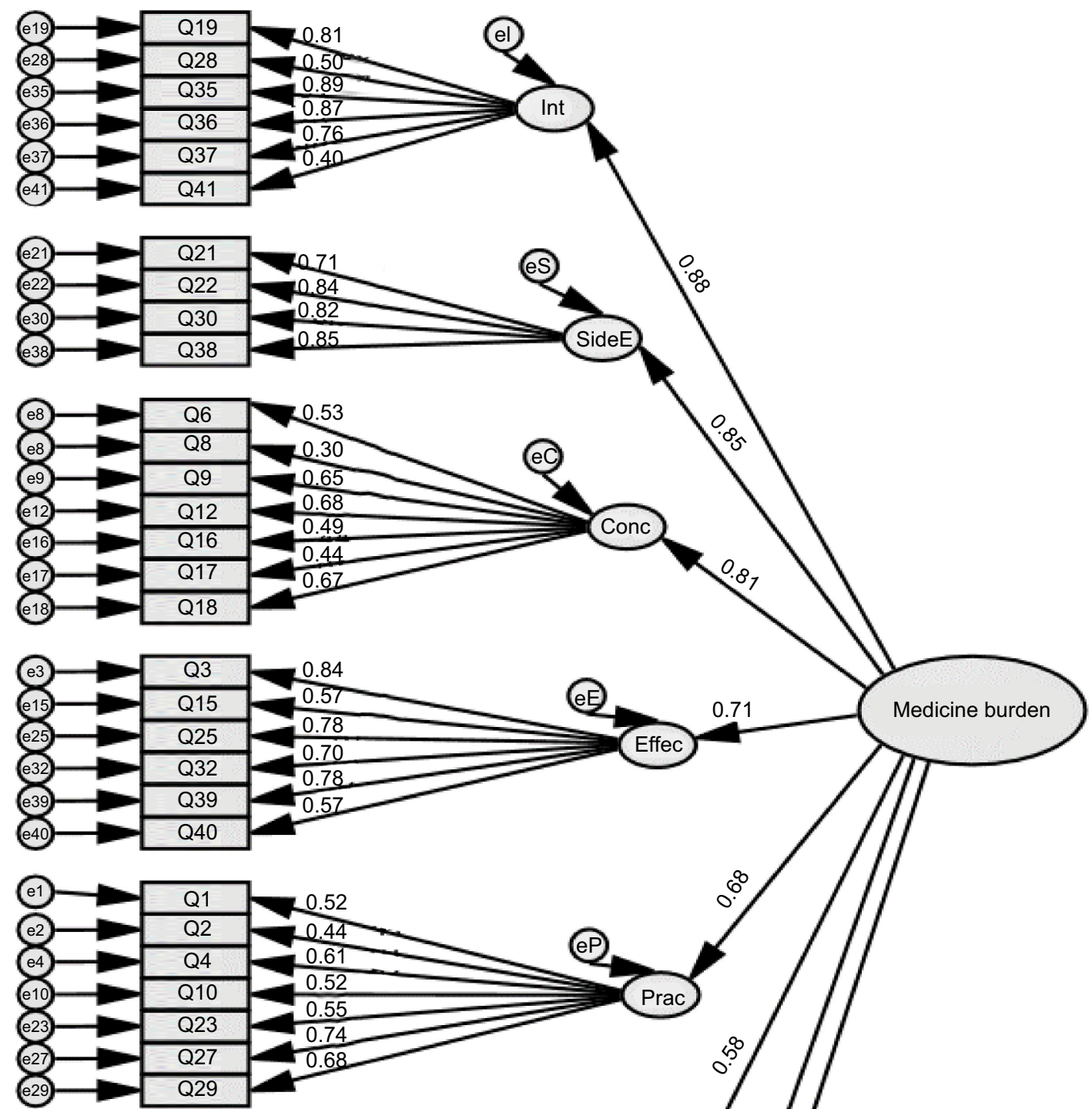

\begin{tabular}{|l|} 
Q1 \\
\hline Q4 \\
\hline Q23 \\
\hline 27 \\
\hline 29
\end{tabular}
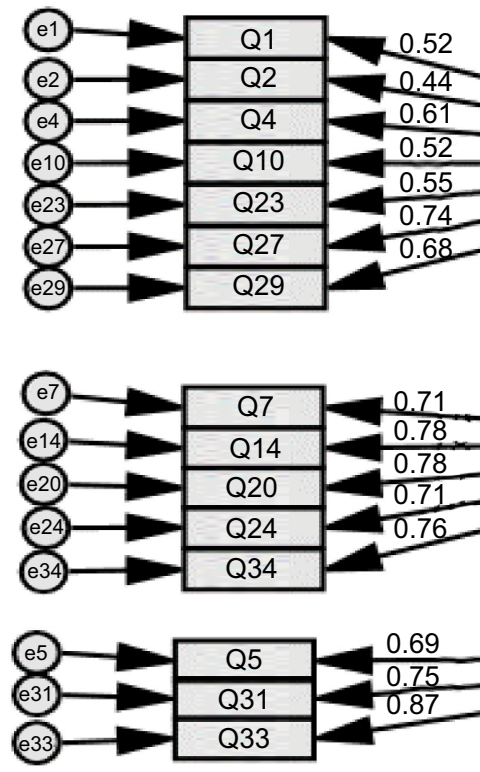

\subsection{9}

(C2)
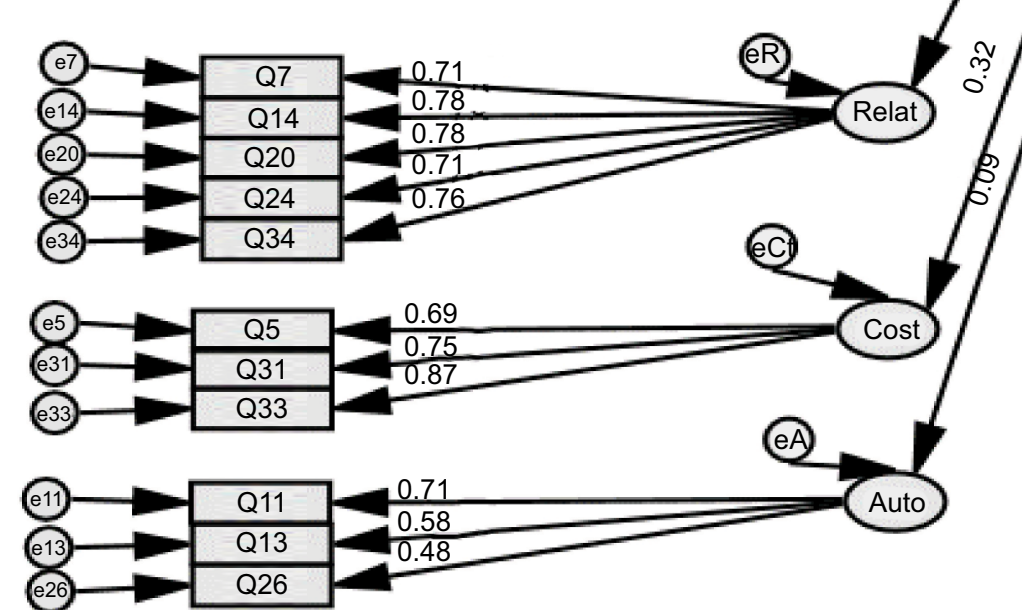

(e)

Figure 2 Hierarchical CFA model for the 41 -item Living with Medicines Questionnaire version 3.

Notes: Standardized path estimates are shown.

Abbreviations: CFA, confirmatory factor analyses; Int, interferences with day-to-day life; SideE, side effects; Conc, general concerns about medicines; Effec, lack of effectiveness; Prac, practical difficulties; Relat, patient-doctor relationships and communication about medicines; Cost, cost-related burden; Auto, lack of autonomy/control over medicine use; el-e4I = variance associated each item; el-eA represent variance associated with each of the eight factors or domains (interferences to autonomy respectively); Q, question. 
Table 3 Correlations between domains of the LMQ-3 and TSQM-II subscales

\begin{tabular}{lllll}
\hline LMQ-3 & $\begin{array}{l}\text { TSQM-II } \\
\text { Satisfaction with } \\
\text { effectiveness }\end{array}$ & $\begin{array}{l}\text { TSQM-II } \\
\text { Satisfaction with } \\
\text { side effects }\end{array}$ & $\begin{array}{l}\text { TSQM-II } \\
\text { Satisfaction with } \\
\text { convenience }\end{array}$ & $\begin{array}{l}\text { TSQM-II } \\
\text { Global } \\
\text { satisfaction }\end{array}$ \\
\hline Lack of effectiveness & $-\mathbf{0 . 6 2 8}$ & -0.376 & -0.424 & -0.57 I \\
Side-effect burden & -0.414 & $-\mathbf{0 . 5 9 7}$ & -0.449 & -0.516 \\
Practical difficulties & -0.367 & -0.405 & $-\mathbf{0 . 5 2 9}$ & -0.426 \\
Patient-doctor communication problems & -0.476 & -0.278 & -0.360 & -0.394 \\
Cost-burden & -0.141 & -0.193 & -0.157 & -0.232 \\
General concerns & -0.406 & -0.469 & -0.401 & -0.410 \\
Interferences with life & -0.360 & -0.560 & $-0.45 I$ & -0.430 \\
Lack of autonomy & 0.139 & $0.010 *$ & 0.121 \\
LMQ-3 total score & -0.554 & -0.623 & $0.057^{*}$ & $-\mathbf{0 . 6 1 6}$ \\
\hline
\end{tabular}

Notes: *Correlations not statistically significant at $p<0.05$ (Spearman's correlation coefficient); correlations in bold indicate strongest associations. Abbreviations: LMQ-3, Living with Medicines Questionnaire version 3; TSQM-II, Treatment Satisfaction Questionnaire with Medication.

Table 4 Known-groups validity of the LMQ-3

\begin{tabular}{llll}
\hline Characteristics & & \multicolumn{2}{l}{$\begin{array}{l}\text { Mean LMQ-3 } \\
\text { total score (SD) }\end{array}$} \\
\cline { 3 - 4 } & & $\mathbf{( N = 3 3 6 )}$ & p-value \\
\hline Age (years) & $18-29$ & $104.6(18.4)$ & \\
& $30-49$ & $108.4(22.4)$ & \\
& $50-64$ & $102.8(20.5)$ & \\
& $\geq 65$ & $98.4(17.5)$ & 0.007 \\
Employment & Employed & $103.2(20.1)$ & \\
& Unemployed & $118.0(21.5)$ & \\
No of medicines & Retired & $98.3(17.3)$ & $<0.00 \mathrm{I}$ \\
& $1-4$ & $100.3(17.7)$ & \\
& $5-9$ & $107.8(23.8)$ & \\
Frequency of use & $\geq 10$ & $104.4(20.3)$ & 0.010 \\
& Once daily & $97.8(16.0)$ & \\
& Twice daily & $101.7(20.0)$ & \\
& Three times daily & $111.4(23.8)$ & \\
& $\geq 4$ times daily & $112.7(22.1)$ & $<0.00 \mathrm{I}$ \\
Managing medicines & Independent & $100.8(19.5)$ & \\
& Requires help & $116.4(17.8)$ & $<0.00 \mathrm{I}$ \\
Paying for & No & $100.6(19.5)$ & \\
prescriptions & Yes & $106.2(20.3)$ & 0.014 \\
\hline Ab & &
\end{tabular}

Abbreviation: LMQ-3, Living with Medicines Questionnaire version 3.

\section{Discussion}

This paper describes a revised version of a measure of overall medicine experiences, conceptualized as medicine burden. The LMQ-3 demonstrated adequate construct validity and was appropriately related to other instruments designed to measure relevant constructs, being negatively related to treatment satisfaction. Differences in medicine burden were shown in relation to key factors, in particular frequency of daily use and need for support with using medicines, and the instrument may also have acceptable test-retest reliability, although this requires confirmation in other studies. The eight domains incorporate all the issues covered by the previous version, with the exception of a domain relating specifically to communication with pharmacists. The inclusion of costrelated burden in this revised version was relevant as demonstrated by its clear association with paying prescription charges. Side effects were strengthened within this version into a separate domain and proved to be one of those most strongly associated with overall medicine burden, in addition to interferences with daily life and general concerns. The autonomy domain was less internally consistent and also loaded less well on the overall burden construct in the second-order model. Our decision to retain it was based on the need for this domain identified in the original qualitative interviews on which the instrument was based. ${ }^{20}$ These interviews found that some people feel powerless to change their regimen and feel constrained as a result, ${ }^{20}$ while others consider the decision whether or not to take any particular medicine is theirs alone. Given that this is fundamental to patient-centered medicine optimization, the autonomy domain was essential to the instrument.

It was notable that total LMQ-3 scores were not strongly related to age and their relationship with the number of medicines was not linear. This suggests that the medicine burden for individuals is dependent on a range of factors, and that neither age nor the number of medicines alone is likely to identify those in need of greater support. Indeed, the frequency with which medicines were administered and the need for support appeared to show relationships with overall burden. As with general treatment burden, any individual's perception of the extent of their own medicine burden will depend on social circumstances and coping skills. However, there was a positive relationship between total LMQ-3 scores and VAS-burden score, suggesting that the instrument does measure the construct of medicine burden. 
A Stage $1 \mathrm{LMQ}-2.1(n=133)$

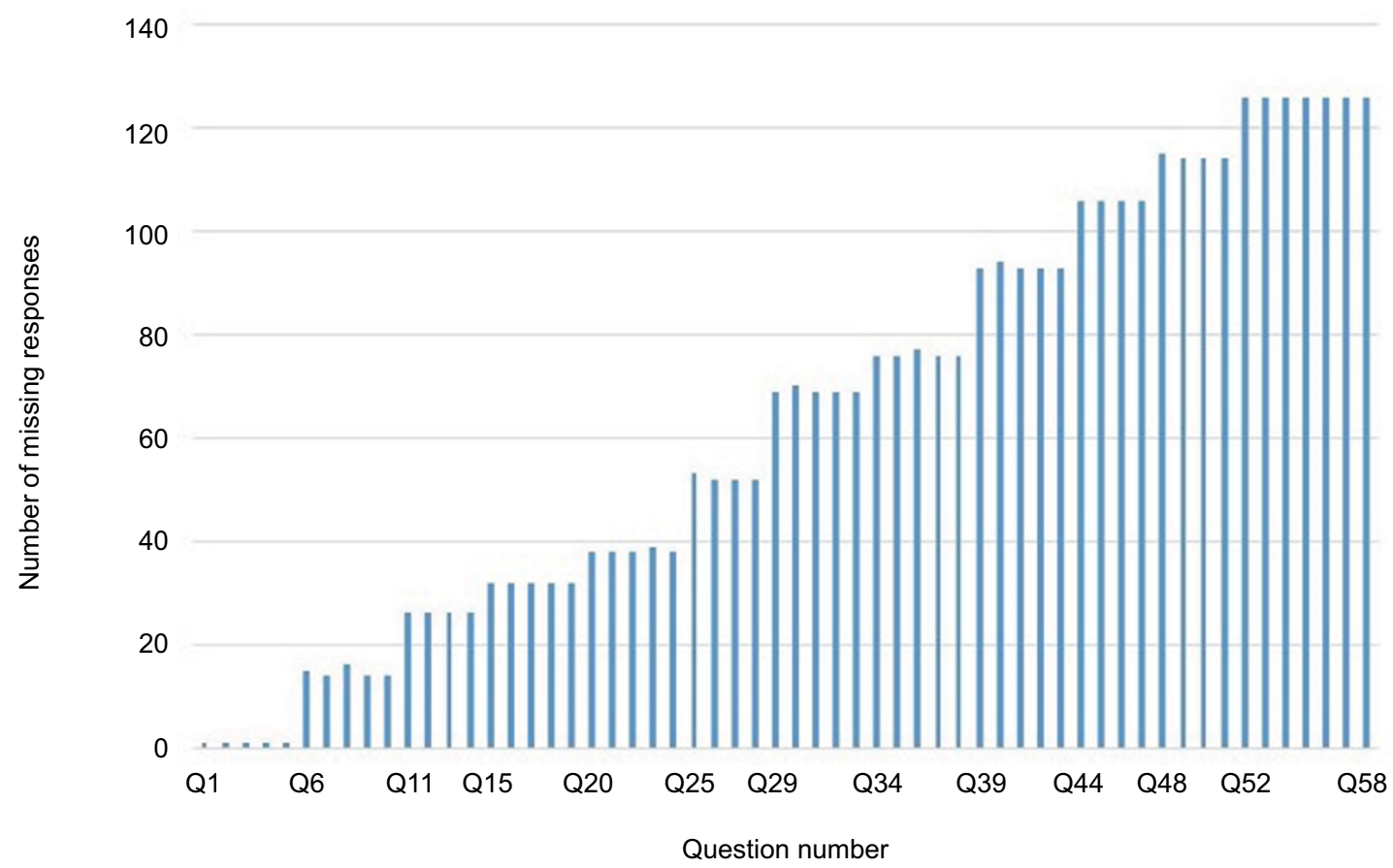

B Stage 2 LMQ-3 $(\mathrm{n}=86)$

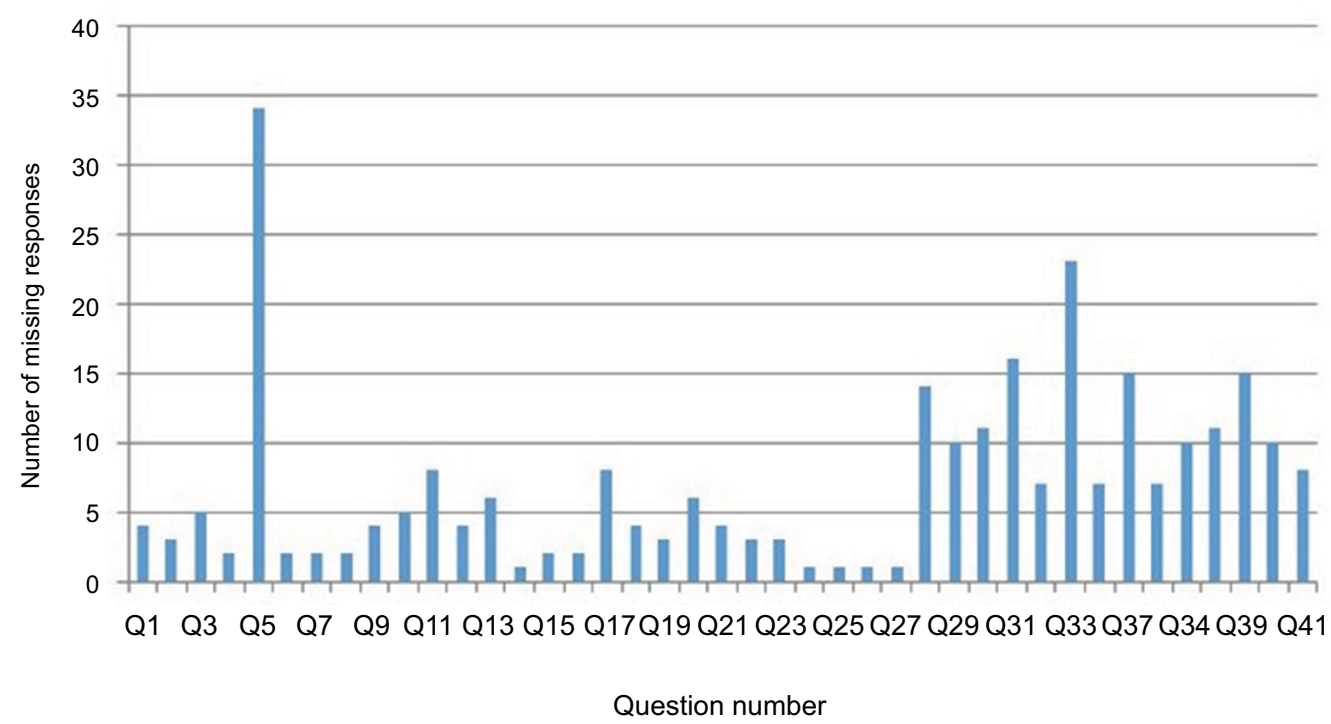

Figure 3 Number of missing responses to LMQ questions.

Abbreviations: LMQ, Living with Medicines Questionnaire; Q, question.

\section{Strengths and limitations}

The LMQ instrument was developed from the patient perspective and the modifications made which resulted in this revised version also used only material derived from and tested by users of long-term medicines. The data used for item generation were drawn from previous studies carried out in 2008 and 2014 and international literature published over several decades, thus covering issues of international and ongoing significance to medicine users.

The development and three stages of testing adhered to standard guidelines for patient-reported outcome measure ${ }^{34,36,37}$ and involved a total of 1197 individuals, both 
Table 5 Items with more than 2\% missing data in Stage 2

\begin{tabular}{|c|c|c|c|}
\hline Item number & Statement & $\begin{array}{l}\text { Number } \\
\text { missing }\end{array}$ & $\begin{array}{l}\text { Percentage } \\
\text { missing }\end{array}$ \\
\hline Q5 & I worry about paying for my medicines. & 34 & 8.1 \\
\hline Q33 & I have to pay more than I can afford for my medicines. & 23 & 5.5 \\
\hline Q31 & I sometimes have to choose between buying basic essentials or medicines. & 16 & 3.9 \\
\hline Q37 & My medicines interfere with my sexual life. & 15 & 3.6 \\
\hline Q39 & My medicines are working. & 15 & 3.6 \\
\hline Q28 & Taking medicines affects my driving. & 14 & 3.3 \\
\hline Q30 & The side effects I get from my medicines are bothersome. & II & 2.6 \\
\hline Q38 & The side effects I get from my medicines adversely affect my well-being. & 11 & 2.6 \\
\hline Q29 & I find using my medicines difficult. & 10 & 2.4 \\
\hline Q34 & The health professionals providing my care know enough about me and my medicines. & 10 & 2.4 \\
\hline Q40 & The side effects are worth it for the benefits I get from my medicines. & 10 & 2.4 \\
\hline
\end{tabular}

Table 6 Differences between full and partial respondents of LMQ-3 in Stage 2

\begin{tabular}{|c|c|c|c|c|}
\hline Characteristics & & $\begin{array}{l}\text { Fully completed } \\
(\mathrm{N}=336)\end{array}$ & $\begin{array}{l}\text { Partially completed } \\
(n=86)\end{array}$ & $p$-value \\
\hline \multirow[t]{2}{*}{ Gender } & Female & $148(47)$ & $38(49)$ & \\
\hline & Male & $186(5 \mid)(n=3 \mid 6)$ & $168(53)(n=78)$ & 0.801 \\
\hline \multirow[t]{4}{*}{ Age group (years) } & $18-29$ & $45(13)$ & $6(7)$ & \\
\hline & $30-49$ & $77(23)$ & $4(5)$ & \\
\hline & $50-64$ & $99(36)$ & $19(22)$ & \\
\hline & $\geq 65$ & $114(34)(n=335)$ & $56(66)(n=85)$ & $<0.001$ \\
\hline \multirow[t]{4}{*}{ Education level } & School & $115(36)$ & $43(57)$ & \\
\hline & Technical college & $98(3 I)$ & $19(25)$ & \\
\hline & University & $81(26)$ & $8(11)$ & \\
\hline & Other & $22(7)(n=3 \mid 6)$ & $17(8)(n=76)$ & 0.004 \\
\hline \multirow[t]{5}{*}{ Employment status } & Employed & $142(43)$ & $17(21)$ & \\
\hline & Unemployed & $39(12)$ & $5(6)$ & \\
\hline & Retired & $129(39)$ & $58(72)$ & \\
\hline & Full-time student & $19(6)$ & $I(I)$ & \\
\hline & Other & $0(n=329)$ & $0(n=8 I)$ & $<0.001$ \\
\hline \multirow[t]{5}{*}{ Ethnicity } & White & $276(84)$ & $77(95)$ & \\
\hline & Asian/Asian British & $14(4)$ & $I(I)$ & \\
\hline & Mixed & $9(3)$ & $I(I)$ & \\
\hline & Black/African/Caribbean & $25(8)$ & $I(I)$ & \\
\hline & Other & $3(1)(n=327)$ & $I(I)(n=8 I)$ & 0.118 \\
\hline \multirow[t]{3}{*}{ Number of medicines } & $1-4$ & $20 \mathrm{I}(6 \mathrm{I})$ & $35(4 I)$ & \\
\hline & $5-9$ & $93(28)$ & $33(39)$ & \\
\hline & $\geq 10$ & $37(\mathrm{II})(\mathrm{n}=33 \mathrm{I})$ & $17(20)(n=85)$ & 0.004 \\
\hline \multirow[t]{2}{*}{ Formulation used } & Tablets/capsules & $299(92)$ & $75(95)$ & \\
\hline & Any other formulation & $26(8)(n=325)$ & $4(5)(n=79)$ & 0.683 \\
\hline \multirow[t]{5}{*}{ Frequency of medicine use } & Once daily & $121(37)$ & $25(3 \mathrm{I})$ & \\
\hline & Twice daily & $101(31)$ & $35(43)$ & \\
\hline & Three times daily & $39(12)$ & $10(12)$ & \\
\hline & $\geq 4$ times daily & $4 I(13)$ & $6(7)$ & \\
\hline & Other times & $23(7)(n=325)$ & $5(6)(n=8 I)$ & 0.269 \\
\hline Assisted in using & No - independent & $286(87)$ & $63(79)$ & \\
\hline medicines & Yes - has a caretaker & $4 I(13)(n=327)$ & $17(2 \mathrm{I})(\mathrm{n}=80)$ & 0.051 \\
\hline \multirow[t]{2}{*}{ Pays for prescriptions } & No & $203(62)$ & $64(80)$ & \\
\hline & Yes & $125(38)(n=328)$ & $16(20)(n=80)$ & 0.002 \\
\hline
\end{tabular}

Abbreviation: LMQ-3, Living with Medicines Questionnaire version 3.

members of the public and patients, recruited using a range of methods from different areas across England and in different health care settings. The overall population included people aged from 18 to 92 years, using between 1 and 26 medicines regularly, with varying frequency of medicines administration and diverse formulations, some who have assistance in 
managing medicines, and some who contribute to paying for medicines. Stage 1 respondents were drawn from the whole of England, whereas those in Stages 2 and 3 were from South East England. However, we have no reason to suppose that patients and members of the public in the South East differ from those across the rest of England in their medicine experiences. The majority of respondents in Stages 1 and 3 , which required access to the Internet, were female, and the samples were biased toward those with higher education levels. In contrast, males were well represented in Stage 2, with respondents also being older and less highly educated. However, the frail or housebound may have been excluded from this stage by virtue of the recruitment methods used. There is no gold standard for measuring medicine burden; hence, we used treatment satisfaction and HRQoL measures to assess criterion validity and confirmed that the LMQ measures a distinct concept. Test-retest assessment assumed that the sample population studied was stable in terms of their prescription medicine use experiences, hence medicine burden, and was not large enough to confirm this aspect of the instrument. Moreover, the length of the instrument is a potential barrier to completion, and some questions may be perceived as of no direct relevance to some individuals. The items covering cost and some social impacts, which this revised instrument was designed to incorporate, may thus need to include alternative responses.

\section{Relevance to research and practice}

Other measures of treatment burden either focus on individual disease states or involve aspects of care beyond medicines, ${ }^{4,13}$ but many of the domains and issues included in these instruments are similar to those covered by the LMQ-3. This suggests that the LMQ-3, as a generic measure of medicine use, may be particularly useful as a patientreported outcome measure in studies designed to reduce the burden of polypharmacy in patients with multimorbidity. The finding that the relationship between medicine burden and the number of medicines is not clear-cut is important for practice. As has been found by others, some individuals may be burdened by relatively few medicines, while others do not perceive large quantities of medicines to be burdensome..$^{4,12,38,39}$ Current guidelines produced by National Institute for Health and Care Excellence on multimorbidity suggest that the number of regular medicines prescribed is used as a marker of increased treatment burden and suggests using an approach which takes into account multimorbidity for those prescribed 10 or more regular medicines or those prescribed fewer than 10 regular medicines who are at particular risk of adverse events. ${ }^{40}$
Further work to confirm reliability, assess sensitivity to change, and to determine whether greater perceived burden relates to adherence and clinical outcomes is desirable. To date, the LMQ-3 has been successfully translated into Ara$\mathrm{bic}^{41}$ and is also being used in studies in several other countries, which will contribute to obtaining a fuller picture of the usefulness of this instrument and provide comparative data on the burden of using long-term medicines across settings.

\section{Acknowledgments}

We thank all study participants, patient organizations, health websites, community pharmacies, general practices, hospital clinics, and the Kent Adult Research Unit that permitted survey distribution. We also thank our undergraduate students for support in data collection. This work was supported by the Medway School of Pharmacy and the Commonwealth Scholarship Commission, as a PhD program. Some preliminary results of this work were presented at the International Social Pharmacy Workshop in Aberdeen, UK (July 2016), and at the Pharmaceutical Care Network Europe Working Conference in Bled, Slovenia (February 2017). The work constitutes part of the $\mathrm{PhD}$ thesis of Barbra Katusiime, which is available online at https://kar.kent.ac.uk/62939/.

\section{Author contributions}

All authors conceived and designed the study. BK conducted the research, including data collection and analysis, and all authors interpreted the findings. All authors contributed to drafting and critical appraisal of the manuscript, and agreed the final version presented. Overall guarantor of the article is JK. All authors contributed toward data analysis, drafting and critically revising the paper and agree to be accountable for all aspects of the work.

\section{Disclosure}

The authors report no conflicts of interest in this work.

\section{References}

1. Barrett K, Lucas E, Alexander GC. How polypharmacy has become a medical burden worldwide. Clinical Pharmacist. 2016;8(6).

2. Guthrie B, Makubate B, Hernandez-Santiago V, Dreischulte T. The rising tide of polypharmacy and drug-drug interactions: population database analysis 1995-2010. BMC Med. 2015;13:1-10.

3. Heaton J, Britten N, Krska J, Reeve J. Person-centred medicines optimisation policy in England: an agenda for research on polypharmacy. Prim Health Care Res Dev. 2017;18:24-34.

4. Tran V-T, Montori VM, Eton DT, Baruch D, Falissard B, Ravaud P. Development and description of measurement properties of an instrument to assess treatment burden among patients with multiple chronic conditions. BMC Med. 2012;10:68.

5. Eton D, Ridgeway J, Egginton J, et al. Finalizing a measurement framework for the burden of treatment in complex patients with chronic conditions. Patient Relat Outcome Meas. 2015;6:117-126. 
6. Duerden M, Avery T, Payne R. Polypharmacy and Medicines Optimisation - Making it Safe and Sound. London: The King's Fund; 2013.

7. Cooper JA, Cadogan CA, Patterson SM, et al. Interventions to improve the appropriate use of polypharmacy in older people: a Cochrane systematic review. BMJ Open. 2015;5:e009235.

8. Ryan R, Santesso N, Lowe D, et al. Interventions to improve safe and effective medicines use by consumers: an overview of systematic reviews. Cochrane Database Syst Rev. 2014;4:CD007768.

9. Royal Pharmaceutical Society. Medicines optimisation: helping patients to make the most of medicines. Good practice guidance for healthcare professionals in England. 2013. Available from: http://www.rpharms. com/promoting-pharmacy-pdfs/helping-patients-make-the-most-oftheir-medicines.pdf. Accessed May 6, 2016.

10. National Institute for Health and Care Excellence. Medicines optimisation: the safe and effective use of medicines to enable the best possible outcomes. NG5. 2015. Available from: https://www.nice.org.uk/guidance/ng5. Accessed February 10, 2017.

11. Bokhof B, Junius-Walker U. Reducing polypharmacy from the perspectives of general practitioners and older patients: a synthesis of qualitative studies. Drugs Aging. 2016;33:249-266.

12. Mohammed MA, Moles RJ, Chen TF. Medication-related burden and patients' lived experience with medicine: a systematic review and metasynthesis of qualitative studies. BMJ Open. 2016;6:1-16.

13. Eton DT, Elraiyah TA, Yost KJ, et al. A systematic review of patientreported measures of burden of treatment in three chronic diseases. Patient Relat Outcome Meas. 2013;4:7-20.

14. Willke RJ, Burke LB, Erickson P. Measuring treatment impact: a review of patient-reported outcomes and other efficacy endpoints in approved product labels. Control Clin Trials. 2004;25:535-552.

15. Krska J, Katusiime B, Corlett SA. Validation of an instrument to measure patients' experiences of medicine use: the Living with Medicines Questionnaire. Patient Prefer Adherence. 2017;11:671-679.

16. Katusiime B, Corlett S, Reeve JL, Krska J. Measuring medicines related experiences from the patient perspective: a systematic review. Patient Relat Outcome Meas. 2016;7:157-171.

17. Schafheutle EI. Patients' views on the UK policy of prescription charges - insights from qualitative interviews. Res Social Adm Pharm. 2008;4:343-354.

18. Prescription Charges Coalition. Paying the price: prescription charges and people with long-term conditions. 2013. Available from: http:// www.prescriptionchargescoalition.org.uk/uploads/1/2/7/5/12754304/ paying_the_price_report.pdf. Accessed March 2, 2017.

19. The Prescription Charges Coalition. Paying the price: prescription charges and employment. 2014. Available from: http://www.prescriptionchargescoalition.org.uk/uploads/1/2/7/5/12754304/prescription_ charges_and_employment_report_feb_2014.pdf. Accessed September 21, 2015.

20. Krska J, Morecroft CW, Poole H, Rowe PH. Issues potentially affecting quality of life arising from long-term medicines use: a qualitative study. Int J Clin Pharm. 2013;35:1161-1169.

21. Pound P, Britten N, Morgan M, et al. Resisting medicines: a synthesis of qualitative studies of medicine taking. Soc Sci Med. 2005;61:133-155.

22. Britten N. Patients' ideas about medicines: a qualitative study in a general practice population. Br J Gen Pract. 1994;44:465-468.

23. Britten N. Medicines and Society: Patients, Professionals and the Dominance of Pharmaceuticals. Hampshire, NY: Palgrave Macmillan; 2008.

Patient Related Outcome Measures

\section{Publish your work in this journal}

Patient Related Outcome Measures is an international, peer-reviewed, open access journal focusing on treatment outcomes specifically relevant to patients. All aspects of patient care are addressed within the journal and practitioners from all disciplines are invited to submit their work as well as healthcare researchers and patient support groups.
24. Anthoine E, Moret L, Regnault A, Sébille V, Hardouin J-B. Sample size used to validate a scale: a review of publications on newly-developed patient reported outcomes measures. Health Qual Life Outcomes. 2014;12:176.

25. Kahn JH. Factor analysis in counseling psychology research, training, and practice principles, advances, and applications. Couns Psychol. 2006;34:684-718.

26. Beavers AS, Lounsbury JW, Richards JK, Huck SW, Skolits GJ, Esquivel SL. Practical considerations for using exploratory factor analysis in educational research. PARE. 2013;18:1-13.

27. Costello A, Osborne J. Best practices in exploratory factor analysis: four recommendations for getting the most from your analysis. PARE. 2005; 10:1-9.

28. Byrne BM. Structural Equation Modeling with AMOS. Basic Concepts, Applications, and Programming. 2nd ed. New York: Taylor and Francis Group LLC; 2010.

29. Kline RB. Principles and Practice of Structural Equation Modeling. 3rd ed. New York: The Guilford Press; 2011.

30. Atkinson MJ, Sinha A, Hass SL, et al. Validation of a general measure of treatment satisfaction, the Treatment Satisfaction Questionnaire for Medication (TSQM), using a national panel study of chronic disease. Health Qual Life Outcomes. 2004;2:12.

31. Atkinson MJ, Kumar R, Cappelleri JC, Hass SL. Hierarchical Construct Validity of the Treatment Satisfaction Questionnaire for Medication (TSQM Version II) among outpatient pharmacy consumers. Value Health. 2005;8:S9-24.

32. Herdman M, Gudex C, Lloyd A, et al. Development and preliminary testing of the new five-level version of EQ-5D (EQ-5D-5L). Qual Life Res. 2011;20:1727-1736.

33. Juniper E, Guyatt G, Jaeschke R. How to develop and validate a new health-related quality of life instrument. In: Spilker B, editor. Quality of Life and Pharmacoeconomics in Clinical Trials. New York: Raven Press; 1996:49-56.

34. Terwee CB, Bot SDM, de Boer MR, et al. Quality criteria were proposed for measurement properties of health status questionnaires. $J$ Clin Epidemiol. 2007;60:34-42.

35. Tabachnick BG, Fidell LS. Using Multivariate Statistics. 6th ed. Boston: Pearson Education; 2013.

36. Mokkink LB, Terwee CB, Patrick DL, et al. The COSMIN checklist for assessing the methodological quality of studies on measurement properties of health status measurement instruments: an international Delphi study. Qual Life Res. 2010;19:539-549.

37. US Department of Health and Human Services Food and Drug Administration. Guidance for industry. Patient-reported outcome measures: use in medical product development to support labeling claims. 2009. Available from: www.fda.gov/downloads/Drugs/GuidanceComplianceRegulatoryInformation/Guidances/UCM193282.pdf. Accessed October 30, 2015.

38. Zarowitz BJ. Polypharmacy: when is enough, enough? Geriatr Nurs. 2011;32:447-449.

39. Cadogan CA, Ryan C, Hughes CM. Appropriate polypharmacy and medicine safety: when many is not too many. Drug Safety. 2016;39:109-116.

40. National Institute for Health and Care Excellence. Multimorbidity: clinical assessment and management. NICE guideline [NG56]. 2016. Available from: https://www.nice.org.uk/guidance/ng56. Accessed August 2, 2017.

41. Zidan A, Awaisu A, Hasan S, Kheir N. The Living with Medicines Questionnaire: translation and cultural adaptation into the Arabic context. Value Health Reg Issues. 2016;10:36-40.

The journal is included in PubMed. The manuscript management system is completely online and includes a very quick and fair peer-review system. Visit http://www.dovepress.com/testimonials.php to read real quotes from published authors. 